\title{
Disease resistance or growth: the role of plant hormones in balancing immune responses and fitness costs
}

\author{
Nicolas Denancé ${ }^{1,2 * \dagger}$, Andrea Sánchez-Vallet ${ }^{3,4,5 t}$, Deborah Goffner ${ }^{1,2}$ and Antonio Molina ${ }^{4,5}$ \\ 1 UMR 5546, Laboratoire de Recherche en Sciences Végétales, Université de Toulouse, Castanet-Tolosan, France \\ 2 UMR 5546, Laboratoire de Recherche en Sciences Végétales, Centre National de la Recherche Scientifique, Castanet-Tolosan, France \\ ${ }^{3}$ Laboratory of Phytopathology, Wageningen University, Wageningen, Netherlands \\ ${ }^{4}$ Centro de Biotecnología y Genómica de Plantas, Instituto Nacional de Investigación y Tecnología Agraria y Alimentaria, Universidad Politécnica de Madrid, \\ Pozuelo de Alarcón, Spain \\ ${ }^{5}$ Departamento de Biotecnología, Escuela Técnica Superior de Ingenieros Agrónomos, Universidad Politécnica de Madrid, Madrid, Spain
}

\section{Edited by:}

Sergi Munné-Bosch, University of Barcelona, Spain

\section{Reviewed by:}

Victor Flors, Universitat Jaume I, Spain

$M^{a}$ Isabel Trillas, Universitat

de Barcelona, Spain

\section{*Correspondence:}

Nicolas Denancé, Laboratoire des Interactions Plantes-Microorganismes, UMR INRA/CNRS 441/2594, 24 Chemin de Borde Rouge, B.P.52627 Auzeville, 31326 Castanet-Tolosan, France.

e-mail: ndenance@toulouse.inra.fr

${ }^{\dagger}$ Nicolas Denancé and Andrea

Sánchez-Vallet have contributed

equally to this work.
Plant growth and response to environmental cues are largely governed by phytohormones. The plant hormones ethylene, jasmonic acid, and salicylic acid (SA) play a central role in the regulation of plant immune responses. In addition, other plant hormones, such as auxins, abscisic acid (ABA), cytokinins, gibberellins, and brassinosteroids, that have been thoroughly described to regulate plant development and growth, have recently emerged as key regulators of plant immunity. Plant hormones interact in complex networks to balance the response to developmental and environmental cues and thus limiting defenseassociated fitness costs. The molecular mechanisms that govern these hormonal networks are largely unknown. Moreover, hormone signaling pathways are targeted by pathogens to disturb and evade plant defense responses. In this review, we address novel insights on the regulatory roles of the $A B A, S A$, and auxin in plant resistance to pathogens and we describe the complex interactions among their signal transduction pathways. The strategies developed by pathogens to evade hormone-mediated defensive responses are also described. Based on these data we discuss how hormone signaling could be manipulated to improve the resistance of crops to pathogens.

Keywords: abscisic acid, auxin, hormone crosstalk, pathogens, salicylic acid, trade-off, virulence factor

\section{INTRODUCTION}

In their natural environments, plants are under continuous biotic stress caused by different attackers (e.g., bacteria, fungi, viruses, oomycetes, and insects) that compromise plant survival and offspring. Given that green plants are the ultimate source of energy for most organisms, it is not surprising that plants have evolved a variety of resistance mechanisms that can be constitutively expressed or induced after pathogen or pest attack (Glazebrook, 2005; Panstruga et al., 2009). Plants have developed molecular mechanisms to detect pathogens and pests and to activate defense responses. The plant innate immune system relies in the specific detection by plant protein recognition receptors (PRRs) of relatively conserved molecules of the pathogen called pathogen-associated molecular patterns (PAMPs). This resistance response is known as PAMP-triggered immunity (PTI). Successful pathogens secrete effector proteins that deregulate PTI. To counteract this, plant resistance $(\mathrm{R})$ proteins recognize effectors and activate effector-triggered immunity (ETI; reviewed in Dodds and Rathjen, 2010).

A fine-tune regulation of these immune responses is necessary because the use of metabolites in plant resistance may be detrimental to other physiological processes impacting negatively in other plant traits, such as biomass and seed production (Walters and Heil, 2007; Kempel et al., 2011). These physiological constrains, together with other factors such as the co-existence of plants with natural attackers, have contributed to drive the evolution of a dynamic and complex network system. Defense layers from separate cellular components and from diverse physiological processes are interconnected to reduce the inherent fitness cost of being well-defended (Chisholm et al., 2006; Panstruga et al., 2009; Schulze-Lefert and Panstruga, 2011). The resistance response is regulated by phytohormones, that are small molecules which synergistically and/or antagonistically work in a complex network to regulate many aspects of plant growth, development, reproduction, and response to environmental cues (Pieterse et al., 2009; Santner et al., 2009; Jaillais and Chory, 2010). Recent progresses have been made in understanding the complex hormone network that governs plant immunity, giving rise to a database containing information of the hormone-regulated genes (e.g., in Arabidopsis thaliana) and the phenotypic description of hormone-related mutants (Peng et al., 2009). In parallel, it has been found that pathogens have developed sophisticated molecular mechanisms to deregulate the biosynthesis of hormones and/or to interfere with hormonal signaling pathways, thus, facilitating the overcoming of plant defense mechanisms (Jones and Dangl, 2006; Dodds and Rathjen, 2010). The essential roles of salicylic acid (SA) and ethylene (ET)/jasmonic acid (JA)-mediated signaling pathways in resistance to pathogens are well described (RobertSeilaniantz et al., 2011a). SA signaling positively regulates plant defense against biotrophic pathogens, that need alive tissue to complete their life cycle, whereas ET/JA pathways are commonly required for resistance to necrotrophic pathogens, that degrade 
plant tissue during infection, and to herbivorous pests (Glazebrook, 2005; Bari and Jones, 2009). Several exceptions for this general rule have been described, and thus SA pathway is also required for plant resistance to particular necrotrophic pathogens, whereas ET/JA pathways were found to be essential for resistance to some biotrophic pathogens (Berrocal-Lobo et al., 2002; Robert-Seilaniantz et al., 2011a). Additionally, other hormones such as auxins and abscisic acid (ABA), originally described for their function in the regulation of plant growth processes and the response to abiotic stresses, have recently emerged as crucial players in plant-pathogen interactions (Mauch-Mani and Mauch, 2005; Kazan and Manners, 2009; Ton et al., 2009; Fu and Wang, 2011). All the phytohormone pathways are linked to each other in a huge, complex and still obscure network. For example, ET, ABA, auxin, gibberellins, and cytokinins pathways are considered as hormone modulators of the SA-JA signaling backbone (Pieterse et al., 2012).

To develop hormone-based breeding strategies aiming to improve crop resistance to pathogens, we need to understand the intricate regulation of hormone homeostasis during plantpathogen interactions, and how pathogens interfere with this hormone regulation. Indeed, manipulation of a plant hormone pathway can result in enhanced resistance to a particular pathogen, but it could also have a strong negative effect on plant growth and resistance to a distinct type of pathogen with a different life style (Holeski et al., 2012). In this review, we will discuss novel insights on the complex role of phytohormones in balancing plant innate immunity and development, with a special focus on the regulatory crosstalk of auxins, SA, and ABA. We will also learn about decoy strategies employed by the attackers to disturb hormonemediated defense responses in plants, and we will describe how misregulation of these hormone pathways leads to strong effects on developmental features and on disease resistance to pathogens. Finally, we will discuss the potential of manipulating hormone homeostasis/signaling to improve crop resistance to pathogen.

\section{HORMONE REGULATORY NETWORKS IN DISEASE RESISTANCE \\ AUXINS}

Auxins are a group of molecules including IAA (indole-3-acetic acid) that regulate many aspects of plant development, such as apical dominance, root gravitropism, root hair, lateral root, leaf, and flower formation, and plant vasculature development (Kieffer etal., 2010; Swarup and Péret, 2012). Both direct and indirect effects of auxins on the regulation of pathogen resistance responses in plants have been described (Kazan and Manners, 2009). Indirect effects may be caused by auxins regulation of development-associated processes, such as cell wall architecture, root morphology, and stomata pattern. For example, treatment of rice with IAA impaired the resistance to Xanthomonas oryzae pv. oryzae probably as a consequence of the activation of the biosynthesis of cell wall-associated expansins that lead to cell wall loosening, which facilitates pathogen growth (Ding et al., 2008).

Auxins can negatively impact plant defense by interfering with other hormone signaling pathways or with PTI (RobertSeilaniantz et al., 2011a). The bacterial PAMP flg22, a peptide from flagellin protein (Boller and Felix, 2009; Pel and Pieterse, 2012), induces an Arabidopsis microRNA (miR393), which negatively regulates the mRNA levels of auxins receptors TIR1 (transport inhibitor response 1), AFB2 (auxin signaling F-box 2), and AFB3. Thus, the flg22-triggered suppression of auxin signaling leads to increased resistance to the bacterium Pseudomonas syringae pv. tomato DC3000 (PstDC3000) and also to the oomycete Hyaloperonospora arabidopsidis (Navarro et al., 2006; Robert-Seilaniantz et al., 2011b). The flg22-induced resistance to these biotrophic pathogens was explained by the observed induction of the SA signaling pathway. Supporting this hypothesis, it was found independently that treatment of Arabidopsis leaves with flg22 induces SA accumulation (Tsuda et al., 2008).

In Arabidopsis, SA treatment stabilizes the Aux/IAA proteins, leading to down-regulation of the expression of auxin-related genes. Moreover, the enhanced susceptibility to $P$. syringae pv. maculicola 4326 (Psm4326) of plants expressing the NahG gene (encoding a bacterial salicylate hydroxylase that degrades SA) is partially reverted by the axr2-1 mutation, that disrupts auxin signaling, further indicating that auxin signaling is part of the SA-induced resistance signaling pathway (Wang etal., 2007). Interaction between SA and auxins was further clarified by the characterization of the regulatory pattern of GH3.5 gene, which is involved in auxin homeostasis in Arabidopsis plants. Lines overexpressing GH3.5 have lower levels of Aux/IAA proteins, overexpression of SA signaling pathway and enhanced resistance to $P$. syringae (Park et al., 2007). Moreover, these transgenic lines also displayed enhanced resistance to abiotic stress and induction of the ABA regulatory pathway (Park et al., 2007).

The conjugated auxin-aspartic acid (IAA-Asp) has been recently reported to play a key role in regulating resistance to the necrotrophic fungus Botrytis cinerea and PstDC3000. In Arabidopsis, tomato, and Nicotiana benthamiana infected with these pathogens there is an enhanced expression of GH3.2 and GH3.4 genes, which encode two enzymes required for conjugation of auxins with Asp. Thus, upon pathogen infection, accumulation of IAA-Asp takes place, promoting the development of disease symptoms in infected plants (Gonzalez-Lamothe et al., 2012). The negative effects of auxins on the activation of plant resistance is further supported by the observed enhanced susceptibility of auxin-treated rice to X. oryzae (Ding et al., 2008) and of auxin-treated Arabidopsis to PstDC3000 (Navarro et al., 2006) and Fusarium culmorum (Petti et al., 2012). Disruption of auxin signaling in Arabidopsis mutants, such as axr1, axr2, and axr3, leads to enhanced resistance to F. oxysporum (Kidd et al., 2011). Nevertheless, auxins have also been shown to positively regulate Arabidopsis immunity as axr2-1 and axr1-1 mutants were more susceptible than wild-type plants to the necrotrophic fungi $B$. cinerea and Plectosphaerella cucumerina (Llorente et al., 2008).

One of the biosynthetic pathways of auxins is partially shared with those required for the biosynthesis of tryptophan-derived antimicrobials, such as indole glucosinolates and camalexin. This might lead to competition for the biosynthetic precursor of auxin and antimicrobials (Barlier et al., 2000; Grubb and Abel, 2006). The recently characterized Arabidopsis wat1 (walls are thin1) mutant exhibits specific enhanced resistance to vascular pathogens such as Ralstonia solanacearum. This response was associated to a misregulation of tryptophan derivatives (i.e., lower 
levels of auxin and indole glucosinolates) specifically in roots, resulting in enhanced levels of SA which is, like tryptophan, a chorismate-derivative (Denancé et al., 2013). Collectively, these data demonstrate that auxins play a central role in balancing plant resistance responses.

\section{ABSCISIC ACID}

Abscisic acid is an isoprenoid compound that regulates developmental processes, such as seed development, desiccation, and dormancy (Wasilewska etal., 2008). In addition, the function of $\mathrm{ABA}$ as a regulator of abiotic stress has been thoroughly described (Shinozaki and Yamaguchi-Shinozaki, 2007). ABA has also emerged as a complex modulator of plant defense responses (Asselbergh etal., 2008; Feng et al., 2012; Sánchez-Vallet et al., 2012). ABA can function as a positive or a negative regulator of plant defense depending on the plant-pathogen interaction analyzed (Mauch-Mani and Mauch, 2005; Asselbergh et al., 2008; Ton et al., 2009). ABA-impaired (biosynthesis or signaling) mutants in tomato (sitiens) and Arabidopsis (abi1-1, abi2-1, aba1-6, aba212, aao3-2, and pyr1pyl1pyl2pyl4) were shown to overexpress defensive-signaling pathways, leading to enhanced resistance to different pathogens such as B. cinerea, P. syringae, F. oxysporum, Plectosphaerella cucumerina, and Hyaloperonospora parasitica (Audenaert et al., 2002; Mohr and Cahill, 2003; de Torres-Zabala et al., 2007; de Torres Zabala et al., 2009; Garcia-Andrade et al., 2011; Sánchez-Vallet et al., 2012). Negative interactions of ABA with the major hormones involved in plant defense response (SA, JA, and ET) have been described by means of exogenous hormone treatments (Yasuda et al., 2008; de Torres Zabala et al., 2009; Sánchez-Vallet et al., 2012). For instance, almost 65\% of the upregulated genes and 30\% of the down-regulated genes in aba1-6 mutant were found to be up- or down-regulated by either ET, JA, or SA treatment (Sánchez-Vallet et al., 2012). Remarkably, these genes constitutively up-/down-regulated in aba1-6 mutant were differentially expressed in Arabidopsis wild-type plants inoculated with Plectosphaerella cucumerina, indicating that they form part of the defensive responses activated upon pathogen infection (SánchezVallet et al., 2012). In addition, ABA plays a direct role in regulating $\mathrm{R}$ (resistance) protein activity. ABA and exposition of plants to high temperature both reduce the nuclear accumulation of SNC1 (suppressor of npr1-1, constitutive1) and RPS4 (resistant to Pseudomonas syringae 4) compromising disease resistance to P. syringae (Mang et al., 2012).

Abscisic acid can also positively regulate the resistance to some pathogens, such as Alternaria brassicicola, $R$. solanacearum, and Pythium irregulare, as ABA-deficient and-insensitive mutants (abi1-1, abi2-1, abi4-1, aba1-6, aba2-12, aao3-2, and npq2-1) were found to be more susceptible than wild-type plants to these pathogens (Adie et al., 2007; Hernandez-Blanco et al., 2007; Flors et al., 2008; Garcia-Andrade et al., 2011). In Arabidopsis, ABA has been shown to be required for JA biosynthesis that is essential for resistance to Pythium irregulare (Adie et al., 2007). This contrasts with the negative interaction of ABA- and JA-signaling in the modulation of Arabidopsis resistance to the necrotrophic fungus Plectosphaerella cucumerina (Sánchez-Vallet et al., 2012). Similarly, although ABA and SA have been shown to function antagonistically in the control of the resistance to some pathogens, they trigger stomata closure to avoid penetration of the bacteria P. syringae in Arabidopsis (Melotto et al., 2006). Plant treatment with flg22 is known to interfere with ABA signaling to induce stomata closure. The ABA- or flg22-induced stomata closure are impaired in lines overexpressing HSC70-1 (heat shock cognate701) and mutants in HSP90 (heat shock protein90; Clément et al., 2011), resulting in an increased susceptibility to both virulent and avirulent strains of $P$. syringae (Hubert et al., 2003; Takahashi etal., 2003; Noël etal., 2007). ABA is a key hormone in Arabidopsis response to $R$. solanacearum infection, as $40 \%$ of the genes up-regulated during the development of wilting symptoms were related to $\mathrm{ABA}$, including those encoding proteins for ABA biosynthesis [i.e., 9-cis-epoxycarotenoid dioxygenase3 (NCED3)] or signaling [i.e., ABA-insensitive1 (ABI1) and ABI5; Hu et al., 2008]. More recently, it has been shown that pre-inoculation of Arabidopsis with an avirulent strain of $R$. solanacearum activates plant resistance to virulent isolates of this bacterium, and this resistance was correlated with the enhanced expression of ABA-related genes that resulted in a hostile environment for the infection development. These results suggest that ABA may be used in biological control of bacterial wilt caused by $R$. solanacearum (Feng et al., 2012).

\section{SALICYLIC ACID}

The function of SA in activating resistance against pathogens has been thoroughly described. In Arabidopsis, SA is synthesized from chorismate (a precursor of tryptophan and, consequently, of auxins) via two pathways, either through phenylalanine or through isochorismate (reviewed in Vlot et al., 2009). This second pathway, in which SID2/ICS1 (salicylic acid induction deficient 2 /isochorismate synthase 1 ) is involved, is activated upon pathogen infection, such as Erysiphe or P. syringae, and after plant recognition of pathogen effectors or PAMPs (Tsuda et al., 2008; Vlot et al., 2009). Deficiency of SA biosynthesis in sid2-1 mutant leads to reduced resistance response in Arabidopsis plants (Nawrath and Métraux, 1999). SA is a regulator of plant resistance to biotrophic and hemibiotrophic pathogens, such as Hyaloperonospora arabidopsidis and $P$. syringae, and it also regulates systemic acquired resistance (SAR), a well-studied type of induced resistance (Glazebrook, 2005). In addition, SA is a central regulator of immunity. It interacts with other signaling pathways (e.g., ET and JA pathways), as a strategy to induce the proper resistance responses and to reduce the associated fitness costs (Vlot etal., 2009; Thaler et al., 2012).

NPR1 (non-expressor of PR genes 1), a well-known central player in SA signaling (Cao et al., 1997), and NPR3 and NPR4 proteins have been recently described as SA receptors (Fu et al., 2012; Wu etal., 2012). NPR1 localizes at the cytosol as an oligomer, and in the presence of SA, redox changes occurs in NPR1 that lead to the dissociation of NPR1 complex and to the translocation of the corresponding monomers to the nucleus. There, NPR1 protein activates the transcription of defensive genes, such as $P R$ (pathogenesis-related protein), by interacting with TGA (TGACG sequence-specific binding protein) transcription factors (Dong, 2004; Tada et al., 2008; Robert-Seilaniantz et al., 2011a). In Arabidopsis, EDS1 (enhanced disease susceptibility 1) is a major node required both for SA-dependent basal resistance against 
virulent pathogens and for the activation of the ETI mediated by the TIR-NB-LRR (Toll-interleukin receptor domain-nucleotide binding domain-leucine rich repeat) resistance proteins (Parker et al., 1996; Falk et al., 1999). EDS1 protein is present in distinct pools at nuclei and cytoplasm, and these two EDS1 locations are required for a complete immune response (Garcia et al., 2010). Several EDS1 interactors have been identified, including PAD4 (phytoalexin deficient4), RPS4, RPS6, SAG101 (senescenceassociated gene101), SRFR1 (suppressor of RPS4-RLD1), and SNC1 (Feys et al., 2001, 2005; Bhattacharjee et al., 2011; Heidrich et al., 2011; Rietz et al., 2011). The EDS1-PAD4 complex is necessary for basal resistance and activation of SA-defense response (Rietz et al., 2011). Indeed mutations in EDS1 and PAD4 lead to reduce resistance to pathogens such as Hyaloperonospora parasitica and deficiency of the SA signaling pathway (Parker et al., 1996; Falk et al., 1999; Jirage et al., 1999). Transcriptional regulation of SA-defensive genes is also mediated by HDA19 (histone deacetylase19) that repressed SA-mediated basal defense to PstDC3000 (Choi et al., 2012). Up-regulation of SA marker genes (PR1, PR2, ICS1, EDS1, PAD4) and over-accumulation of SA take place in hda19 mutant, which correlates with its enhanced resistance phenotype to PstDC3000 pathogenic bacteria. Indeed, HDA19 targets $P R 1$ and $P R 2$ promoters to regulate gene expression. The mutation $h d a 19$ causes hyper-acetylation of histones in the promoters of $P R$ genes and priming of SA-associated plant defense (Choi et al., 2012).

Negative crosstalk between SA and JA signaling pathways has been thoroughly described (Gimenez-Ibanez and Solano, 2013). For example, WRKY33, a positive regulator of JA-related genes, is a repressor of the SA pathway. In the wrky33 mutant there is an enhanced expression of several SA-regulated genes (SID2/ICS1, EDS5/SID1, PAD4, EDS1, NIMIN1, PR1, PR2, $P R 3)$ and increased accumulation of SA levels. In turn, SA induction contributes to down-regulate JA-signaling, and to increase the susceptibility of wrky33 plants to necrotrophic fungi (Birkenbihl etal., 2012; Sánchez-Vallet etal., 2012). NPR1 is a regulator of SA-mediated suppression of the JA/ET signaling pathway, as revealed using nprl mutant (Spoel et al., 2003). The Arabidopsis mediator subunit 16 (MED16) was recently described to be a positive regulator of SA-induced defense response and a negative regulator of JA/ET signaling pathway (Zhang etal., 2012). The negative crosstalk between SA and JA is exploited by $P$. syringae strains producing the phytotoxin coronatine (COR), an structural mimic of the active JA-Ile, to suppress SA signaling (Uppalapati et al., 2005; Zheng et al., 2012). P. syringae strains impaired in production of COR have reduced virulence on Arabidopsis wild-type plants but not on SA-deficient lines (e.g., sid2 and NahG; Brooks et al., 2005). In a search for Arabidopsis mutants in which the virulence of COR-deficient PstDC3000 mutant was recovered, several scord (susceptible to coronatine-deficient PstDC3000) mutants were found to be defective in SA signaling (Zeng etal., 2011). For instance, scord3 mutant plants are impaired in EDS5/SID1, a key protein required for SA biosynthesis, and consequently it has reduced SA levels compared with wild-type plants (Zeng et al., 2011), further corroborating the role of SA in resistance to pathogens.

\section{DECOY STRATEGIES OF PATHOGENS: MANIPULATION OF THE HOST HORMONE MACHINERY PATHOGENS PRODUCE AND DEGRADE HORMONES \\ Auxins}

Many pathogenic microbes and plant growth promoting rhizobacteria have evolved complete pathways for auxin biosynthesis with tryptophan as the main precursor (Spaepen et al., 2007). Auxin-producing phytopathogenic bacteria are mostly, but not exclusively, gall-inducing microbes. They include, for instance, Agrobacterium tumefaciens (Liu and Nester, 2006), Agrobacterium rhizogenes (Gaudin and Jouanin, 1995), Erwinia chrysanthemi (Yang et al., 2007), Erwinia herbicola (Brandl and Lindow, 1998), Pseudomonas fluorescens (Suzuki et al., 2003), P. putida (Leveau and Lindow, 2005), Pseudomonas savastanoi (Glickmann et al., 1998), P. syringae (Glickmann etal., 1998), R. solanacearum (Sequeira and Williams, 1964; Valls et al., 2006), and Rhodococcus fascians (Vandeputte et al., 2005). In R. solanacearum, auxin biosynthesis is governed by HrpG, a major regulator of bacterial virulence and response to metabolic signals (Valls et al., 2006). In Agrobacterium tumefaciens, two genes required for conversion of tryptophan to auxin are localized on the T-DNA region of the Ti plasmid injected into plant cells. Auxin biosynthesis is necessary for tumor gall formation and for pathogenicity of Agrobacterium (Lee et al., 2009): auxins negatively regulate the expression of genes necessary for the transfer of Agrobacterium T-DNA in plants and also inhibit the growth of several bacterial species in vitro (Liu and Nester, 2006).

Auxin biosynthesis in fungal pathogens seems to be limited to a few species. In Ustilago maydis, U. esculenta, and U. scitaminea auxin is produced (Chung and Tzeng, 2004; Reineke et al., 2008). In this case, auxin does not seem to be required for U. maydis-induced tumor formation or for pathogenicity, as a mutant defective in four genes encoding key auxin biosynthetic enzymes was compromised in auxin levels but not in tumor formation (Reineke et al., 2008). Additionally, other fungi have enzymatic tools to produce auxins, such as Colletotrichum gloeosporioides f. sp. aeschynomene, Colletotrichum acutatum, and F. proliferatum (Robinson et al., 1998; Chung et al., 2003; Maor et al., 2004; Tsavkelova et al., 2012). Nevertheless, the production of auxins by fungal pathogens has not been clearly demonstrated to be a virulent factor that favors plant colonization.

\section{Abscisic acid}

Several fungal species produce ABA, including B. cinerea, Rhizoctonia solani, Ceratocystis fimbriata, and Rhizopus nigricans (Dörffling et al., 1984; Inomata et al., 2004a). ABA biosynthesis by B. cinerea requires a cluster of four genes, $B C A B A 1$ to $B C A B A 4$ (Hirai et al., 2000; Inomata etal., 2004b; Siewers et al., 2004, 2006). Unlike plants, fungi, such as B. cinerea and Cercospora sp., use the mevalonate pathway to produce ABA (Hirai et al., 2000; Inomata et al., 2004a). The role of ABA as a B. cinerea virulence factor has not been fully demonstrated, but several published data support this hypothesis: (i) ABA biosynthesis in the fungus is stimulated by the host plant (Kettner and Därffling, 1995); (ii) exogenous treatment with $\mathrm{ABA}$ increased disease symptoms caused by the fungus on roses (Shaul et al., 1996); and (iii) ABA contributes to susceptibility to $B$. cinerea and other pathogens by suppressing 
defense responses in plants (Audenaert et al., 2002; Sánchez-Vallet et al., 2012).

\section{Salicylic acid}

Although SA biosynthesis has not been described in plant pathogens, it is known that some plant-associated bacteria can degrade salicylate. Indeed, the enzyme salicylate hydroxylase (NahG), that catalyzes the formation of catechol from salicylate, has been identified in various bacteria, such as $P$. putida and $P$. fluorescens (You et al., 1991; Chung et al., 2001).

\section{PATHOGEN EFFECTORS INTERFERE WITH HORMONE SIGNALING IN PLANTS}

Effectors are proteins secreted by pathogens during infection to deregulate host immune responses. One common strategy implemented by effectors is the manipulation of the homeostasis of plant phytohormones, resulting in deactivation of the appropriate defense response (Robert-Seilaniantz et al., 2007; Bari and Jones, 2009; Figures 1 and 2).

\section{Bacteria and phytoplasma}

In addition to the common example of the phytotoxin COR produced by $P$. syringae strains to manipulate the plant hormonal balance (Zheng et al., 2012), many phytopathogenic bacteria have developed large repertoires of type III effectors (T3E) which are necessarily injected through the syringe-like type III secretion system inside plant cells to deregulate plant immunity (Figure 1; Jones and Dangl, 2006; Boller and He, 2009; Büttner and He, 2009). The roles of bacterial effectors in plant immunity have been extensively reviewed elsewhere (Cui et al., 2009; Rivas and Genin, 2011; Deslandes and Rivas, 2012; Dou and Zhou, 2012; Howden and Huitema, 2012). Xanthomonas sp. bacteria synthesized TAL (transcription activator-like) effectors, such as AvrBs3 from $X$. axonopodis pv. vesicatoria (formerly $X$. campestris pv. vesicatoria), that are imported to the plant nuclei where they activate the expression of host target genes (Boch et al., 2009; Moscou and Bogdanove, 2009; Bogdanove et al., 2011). Five targets, designed as up-regulated by AvrBs3 1 to 5 (UPA1-5), are auxin-induced genes members of the SAUR (small auxin up RNA) family (Marois

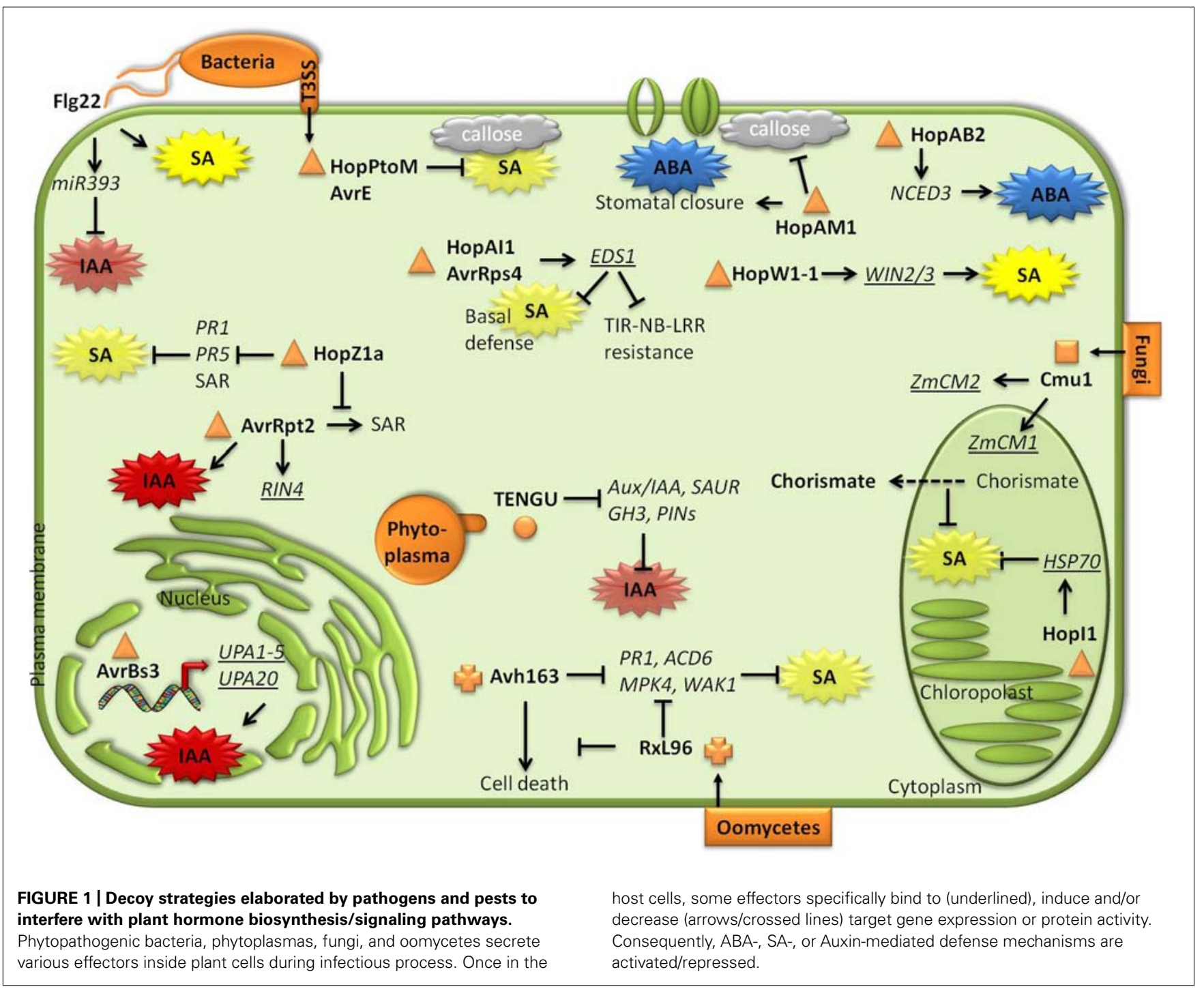




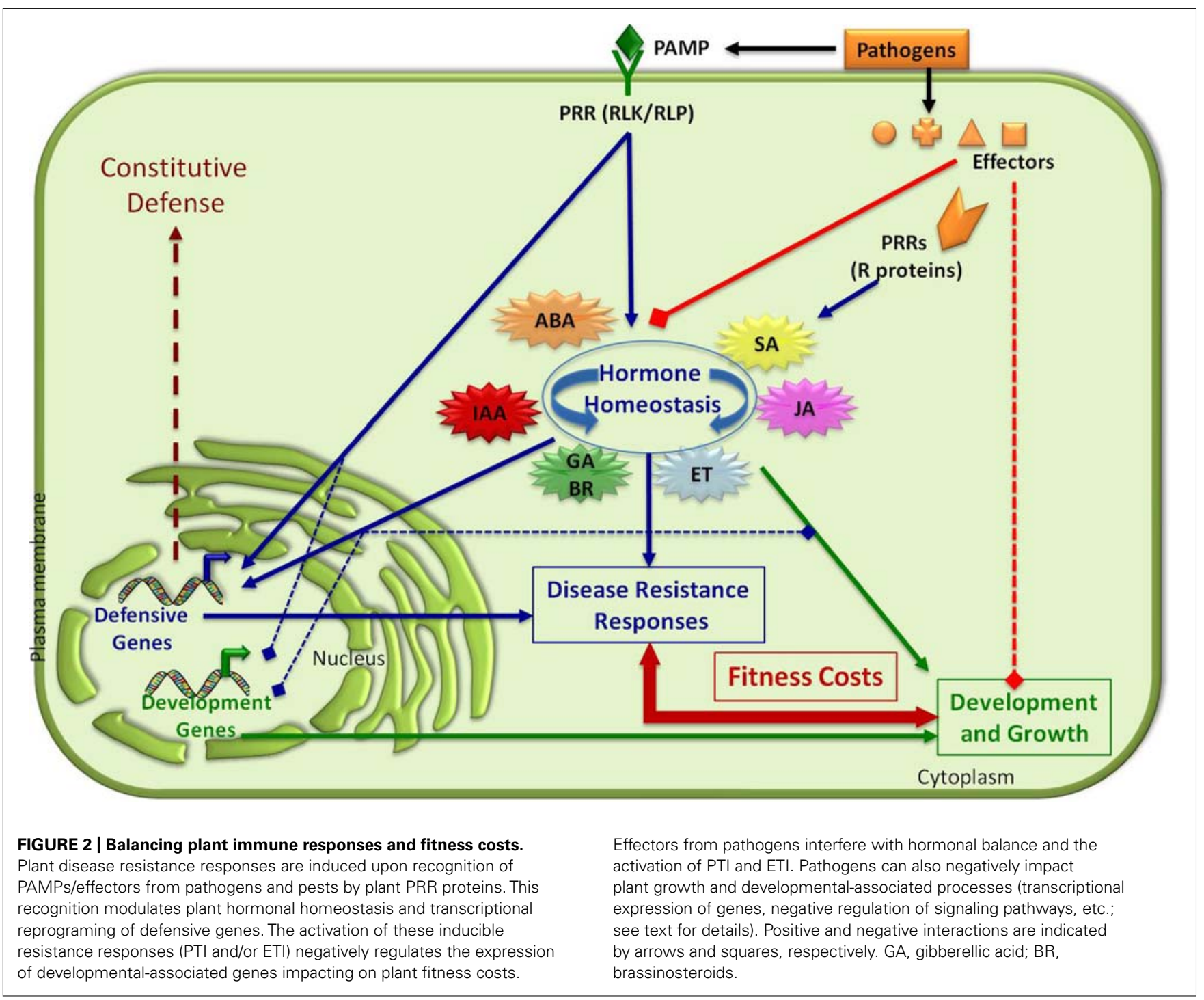

et al., 2002). Additionally, induction of the TAL target UPA20 provokes cell hypertrophy, a feature which is characteristic of auxin accumulation (Kay et al., 2007). Auxin is a susceptibility factor in Arabidopsis plants infected with PstDC3000, and consequently, auxin was hypothesized to be a potential target for bacterial effectors. Thus, the cysteine protease bacterial effector AvrRpt 2 triggers auxin signaling pathway to enhance bacterial virulence in Arabidopsis lines lacking the resistance gene that normally recognizes this T3E. Transgenic plants expressing AvrRpt2 accumulated higher auxin levels and showed a constitutive activation of the auxin signaling pathway. Additionally, auxin levels in Arabidopsis leaves inoculated with PstDC3000avrRpt2 were higher than those in plants infected with PstDC3000 (Chen et al., 2007), indicating that AvrRpt 2 modulates auxin pathway to enhance bacterial virulence, but this effect was found to be independent of SA (Chen et al., 2004). Auxin signaling seems to be a preferential target of phytoplasmas, some bacteria-like, obligate plant pathogens belonging to the class of Mollicutes that require sap-feeding insect herbivores as vectors for transmission to plants (Sugio et al., 2011).
Indeed, TENGU (tengu-su inducer) is an effector of Candidatus phytoplasma asteris that, when expressed in Arabidopsis transgenic lines, causes dwarfism and abnormal reproductive organogenesis and flower sterility. These phenotypes, which are similar to the disease symptoms provoked by the phytoplasma, have been associated to alterations in hormone balance. Microarray analysis of transgenic Arabidopsis plants expressing TENGU demonstrated that many auxin-related genes were down-regulated, including genes of the Aux/IAA, SAUR, GH3, and PIN families (Hoshi et al., 2009). Thus, TENGU effector could interfere with auxin signaling in plants.

Several P. syringae effectors target SA. HopPtoM and AvrE are repressors of SA-dependent callose deposition but do not affect SA-responsive genes in Arabidopsis infected leaves (DebRoy et al., 2004). The effector HopI1 (previously named HopPmaI), that is essential for the virulence of $P$. syringae pv. maculicola (Pma) in Arabidopsis, N. benthamiana, and N. tabacum, has been found to be a modulator of SA-mediated defense responses. Indeed, the expression of HopI1 in Arabidopsis acd6-1 (accelerated cell 
death6-1) mutant reduces the enhanced SA levels and the constitutive induction of defense responses characteristic of this mutant (Jelenska et al., 2007). Another effector, HopZ1a, a cysteine protease from $P$. syringae that interferes with SA signaling, is able to suppress PstDC3000-induced expression of PR1 and PR5 and the SAR induced either by PstDC3000 (virulent) or PstDC3000avrRpt2 (avirulent) pathogens (Macho et al., 2010). Thus, HopZla contributes to Pst virulence by suppressing SAmediated defenses that takes place during ETI induced by other effectors such as AvrRpt2. EDS1, a key regulatory node of basal and induced resistance, is also targeted by bacterial pathogen effectors. AvrRps4 and HopA1, two PstDC3000 effectors, bind to EDS1 interfering with the interaction between EDS1 and TIR-NB-LRR resistance proteins, and consequently preventing the activation of the immune response (Bhattacharjee et al., 2011; Heidrich et al., 2011). In contrast to other effectors, HopW1-1, that forms part of the T3E repertoire of Pma, but not of that of PstDC3000 (Guttman et al., 2002), induces resistance in the Ws accession of Arabidopsis to Pma (Lee et al., 2008). This effect of HopW1-1 on Ws was corroborated by the fact that PstDC3000 strain expressing HopW1-1 has reduced growth and caused weak disease symptoms in the Ws plants. In a yeast two-hybrid screen, three Arabidopsis HopW1-1-interacting proteins (WIN2, WIN3) were found to bind to the effector (Lee et al., 2008). The enhanced resistance triggered by HopW1-1 was not caused by activation of a hypersensitive response, but it was dependent on an enhanced accumulation of SA. Indeed, pad4 mutants were almost completely compromised in their resistance response to HopW1-1.

HopAM1 contributes to $P$. syringae virulence by manipulating ABA-mediated responses in plants: it enhances stomata closure, suppresses infection-triggered callose deposition, and inhibits seed germination. Remarkably, HopAM1 increased P. syringae virulence on Arabidopsis plants grown under water-stressed conditions (Goel et al., 2008). Arabidopsis lines expressing HopAM1 showed enhanced colonization by the avirulent PstDC3000 hrcCmutant, impaired in T3SS, and did not develop callose-rich papillae that are normally induced by $h \mathrm{rcC}^{-}$strain in wild-type plants (Goel et al., 2008). An effector of P. syringae pv. phaseolicola, HopAB2, promotes virulence on Arabidopsis and bean plants, and suppresses basal resistance to PstDC3000 hrpA ${ }^{-}$, a mutant compromised in T3SS (de Torres et al., 2006). Expression of HopAB2 in Arabidopsis plants induces the expression of NCED3, resulting in enhanced biosynthesis of $\mathrm{ABA}$, which interferes with the accumulation of SA levels and the activation of SA-mediated resistance (de Torres-Zabala et al., 2007). Thus, HopAM1 and HopAB2 are suppressors of defense mechanisms by enhancing $\mathrm{ABA}$ responses and promoting disease susceptibility in plants.

\section{Filamentous pathogens: oomycetes and fungi}

Oomycete genomes contain a class of cytoplasmic proteins known as RXLRs that contain a conserved RXLR amino acid motif (arginine, any amino acid, leucine, arginine; Rehmany etal., 2005; Morgan and Kamoun, 2007). Two effectors from this class, HaRxL96 from Hyaloperonospora arabidopsidis, the causal agent of downy mildew on Arabidopsis, and its ortholog PsAvh163 from Phytophthora sojae, which causes soybean rot disease, interfere with plant immunity (Anderson et al., 2012). Remarkably, Arabidopsis plants expressing HaRxL96 or PsAvh163 became more susceptible to virulent and avirulent pathogens, indicating that these effectors repress basal resistance and ETI. In fact, the induction of SA-defensive genes, but not SA biosynthesis, that take places upon infection with avirulent strains of Hyaloperonospora arabidopsidis, was suppressed in the transgenic lines expressing HaRxL96 or PsAvh163, indicating that these effectors interfere with SA signaling to trigger plant susceptibility to oomycetes (Anderson et al., 2012).

Filamentous extracellular or obligate fungal pathogens secrete effectors via hyphae or haustoria (Stergiopoulos and de Wit, 2009; de Jonge etal., 2011). U. maydis is a basidiomycete fungus that causes smut disease on maize and its relative teosinte (Brefort et al., 2009; Djamei and Kahmann, 2012). Maize infection by $U$. maydis results in the repression of SA-associated PR1 defense gene expression during the early biotrophic phase of the interaction, while auxin production in the host is induced later during tumor formation (Doehlemann et al., 2008). One of the most highly expressed genes of $U$. maydis during plant colonization is the Cmul effector, a chorismate mutase protein (Skibbe et al., 2010). Cmul is required for full virulence since the induction of tumors is significantly reduced in a $U$. maydis cmu1 mutant (Djamei et al., 2011). Once inside plant cells, Cmul is localized in the cytoplasm, the nucleus and guard cells and it is spread to neighbor cells through plasmodesmata. A yeast two-hybrid analysis showed that Cmul interacts with two maize chorismate mutases, $\mathrm{ZmCm} 1$ and $\mathrm{ZmCm} 2$, which are found in plastids and cytoplasm in plants, respectively. Interestingly, SA levels were higher in maize inoculated with a cmul mutant than with a wild-type strain, resulting in an increased resistance of the mutant to $U$. maydis. It was hypothesized that Cmul could act together with $\mathrm{ZmCm} 2$ in the plant cytoplasm to enhance the flow of the SA-precursor chorismate from the plastid (where SA biosynthesis takes place) to the cytosol. Consequently, in plastids, less chorismate would be available for SA biosynthesis (Djamei et al., 2011). These results indicate that SA biosynthesis pathway of maize is hijacked by U. maydis as a mechanism of virulence. Interestingly, such a mechanism was also described for the soybean cyst nematode Heterodera glycines and the root-knot nematode Meloidogyne javanica (Bekal et al., 2003; Doyle and Lambert, 2003). The virulence factor of Cladosporium fulvum Avr2 targets the tomato papain-like cysteine protease (PLCP) RCR3 and Phytophthora-inhibited protease 1 (PIP1) in order to deregulate basal immunity. RCR3 and PIP1 are specifically induced by treatment of tomato plants with the SA analog benzothiadiazole (BTH). Therefore, Avr2 seems to interfere with tomato SA signaling pathway (Shabab et al., 2008).

\section{FITNESS COSTS OF DEFENSE RESPONSES REGULATED BY PHYTOHORMONES}

The involvement of many plant growth regulatory phytohormones in the control of plant resistance responses to both biotic and abiotic stresses indicates the existence of a tight interconnection between two physiological processes: development and adaptation to environmental cues. The regulatory potential of the hormone network allows plants to quickly respond to environmental 
changes and, thus, to use the limited nutrient resources in a costefficient manner. This hypothesis is based on the idea that being well-defended (i.e., having strong, pre-existing defensive mechanisms) may not always be the best defensive strategy, most likely because allocation of metabolites and proteins to resistance may constrain other plant physiological processes (Walters and Heil, 2007; Manzaneda et al., 2010; Kempel et al., 2011). In line with this hypothesis, it is generally believed that hormone-induced resistance evolved to save energy under enemy-free conditions, as they will only incur energy costs when these defensive mechanisms are activated upon pathogen infection or insect attack (Walters and Heil, 2007). However, pathogens and pests evolve to get adapted to the continuous exposure to defensive genetic traits (i.e., antibiotic or antideterrent proteins and/or metabolites). Therefore, it is also possible that hormone-induced resistance evolved to slow down the potential adaptation of putative attackers to these biochemical barriers (Walters and Heil, 2007). All these physiological constrains, together with the co-existence of plants with natural attackers, have evolutionary driven the selection of plant innate immune system.

In different plant species there have been characterized mutants or transgenic lines showing constitutive activation of defensive mechanisms and enhanced resistance to particular pathogens. These resistance phenotypes are generally associated with the misregulation of particular hormone signaling pathways (RobertSeilaniantz etal., 2011a). The characterization of these mutants and transgenic plants has contributed to the identification of the molecular components involved in hormone biosynthesis and signaling pathways, and to the discovery of cross-regulatory nodes among these signaling pathways. Thus, Arabidopsis mutants constitutively overexpressing a specific hormone-dependent pathway (SA, ET, JA, ET + JA, etc.) show enhanced resistance to particular type of pathogens (reviewed by Robert-Seilaniantz et al., 2011a; Holeski et al., 2012). However, this enhanced, constitutive resistance negatively impact plant fitness as these mutants have phenotypic alterations such as dwarfism, spontaneous lesions in different organs, accelerated senescence, delayed flowering, sterility, or reduced seed production (for a review, see RobertSeilaniantz et al., 2011a; Holeski et al., 2012; Thaler et al., 2012). These data indicate that plants have genetic determinants to fine-tune fitness/resistance balance. An example of this fine-tune regulation is represented by the SA receptor NPR3, that is a negative regulator of defensive response during Arabidopsis early flower development through its interaction with NPR1 and TGA2. Remarkably, the nrp3 plants exhibit increased resistance to $P$. syringae infection of immature flowers, but showed reduced fitness in comparison to that of wild-type plants (Shi et al., 2012).

Alteration of a particular hormone signaling pathway generally results in the miss-regulation of other signaling pathways due to the described complex regulatory network that exist among hormones. Thus, the negative cross-regulations among hormone pathways, such as auxin, ABA, and SA described in this review, lead to alterations in the pattern of resistance to natural attackers. That is, enhanced resistance to a particular pathogen (i.e., necrotroph) can be achieved in some of these mutants, but they generally undergo increased susceptibility to a different one (i.e., biotroph; Spoel et al., 2007; Robert-Seilaniantz et al., 2011a). In some particular cases, such as in the ABA-deficient mutant abal, broad spectrum resistance to both necrotrophic and biotrophic pathogen is observed, but this phenotype is also linked to a reduced adaptation of the mutant to abiotic stresses such as drought (Audenaert etal., 2002; de Torres-Zabala et al., 2007; de Torres Zabala et al., 2009; Garcia-Andrade et al., 2011; Sánchez-Vallet et al., 2012). As in nature, plants are exposed to many different biotic agents, but also to abiotic stress, hormone homeostasis is critical in the establishment of appropriate and effective defensive responses of plant against natural attackers and/or abiotic stresses in an ecological context (Figure 2). In line with the hypothesis of the critical role of hormones in balancing growth and response to environmental cues, it has been recently demonstrated that brassinosteroids, that control several developmental-associated processes, also modulate the efficiency of PTI in Arabidopsis (Belkhadir et al., 2012). The interaction between these two types of environmental stresses (biotic and abiotic) requires a complex adaptive molecular response involving many factors that we are just starting to understand (reviewed in Atkinson and Urwin, 2012).

Expressing constitutive resistance by the modification of hormone homeostasis/signaling encounters the risk of allocating resources to defense in the absence of natural pathogens and of impairing defensive mechanisms against particular natural attackers. One alternative to the constitutive, long-lasting activation of induced resistance is to fine-tune plant resistance mechanism by modulating the "immunological memory" of plants, as it has been described in animals (Conrath, 2011). An interesting phenomenon in this context is the so-called "priming" that is a condition whereby plants that have been subjected to prior attack will respond more quickly or more strongly to a subsequent attack. Given that resources are not committed until the threat returns, priming is thought to be a relatively low-cost mechanism of advancing plant defense (Conrath, 2011). Remarkably, the resistance response in primed plants treated with a low, non-effective concentration of a defensive hormone is also faster and stronger than that in non-primed plants (Conrath, 2011). It has been recently demonstrated the existence of an epigenetic regulation of priming, which explain the lack of significant transcriptional changes in primed plants unless they are exposed to the priming agent/hormone (Luna et al., 2012; Slaughter et al., 2012). The genetic control of priming shows similarities to the genetic mechanisms that regulate transgenerational defense induction in plants, such as the SA-dependent SAR and the inherited JA-dependent defense (Holeski et al., 2012; Thaler et al., 2012; Zheng et al., 2012). Similarly, transgenerational priming has been also described (Luna et al., 2012; Slaughter et al., 2012). All these epigenetically inherited changes in defense can strongly alter plant responses to jasmonate and salicylate in offspring and therefore might negatively impact plant resistance to particular type of pathogens (Latzel et al., 2012; Luna et al., 2012).

Though all the published data clearly indicate a fitness cost associated to the constitutive activation of hormone-mediated resistance mechanisms, it must be considered that these experiments were generally performed under laboratory conditions, without nutrient limitations and ecological constraints (i.e., plants were infected with just one pathogen). Long-term experiments 
with model and crop plants under field conditions should be done to determine the potential use of hormone-mediated resistance in crop protection, as these experiments will provide information on the hormone-mediated effectiveness of disease control, but also on plant trade-offs and changes in the population structure of pathogens and pests. Also, a better understanding of the molecular and genetic mechanisms regulating hormonemediated resistance would be required to successfully manipulate hormone homeostasis/signaling and improve crop resistance to pathogens.

\section{REFERENCES}

Adie, B. A., Perez-Perez, J., Perez-Perez, M. M., Godoy, M., Sanchez-Serrano, J. J., Schmelz, E. A., etal. (2007). ABA is an essential signal for plant resistance to pathogens affecting JA biosynthesis and the activation of defenses in Arabidopsis. Plant Cell 19, 1665-1681.

Anderson, R. G., Casady, M. S., Fee, R. A., Vaughan, M. M., Deb, D., Fedkenheuer, K., et al. (2012). Homologous RXLR effectors from Hyaloperonospora arabidopsidis and Phytophthora sojae suppress immunity in distantly related plants. Plant J. 72, 882-893.

Asselbergh, B., De Vleesschauwer, D., and Hofte, M. (2008). Global switches and fine-tuning-ABA modulates plant pathogen defense. Mol. Plant Microbe Interact. 21, 709-719.

Atkinson, N. J., and Urwin, P. E. (2012). The interaction of plant biotic and abiotic stresses: from genes to the field. J. Exp. Bot. 63, 3523-3543.

Audenaert, K., De Meyer, G. B., and Hofte, M. M. (2002). Abscisic acid determines basal susceptibility of tomato to Botrytis cinerea and suppresses salicylic acid-dependent signaling mechanisms. Plant Physiol. 128, 491-501.

Bari, R., and Jones, J. D. (2009). Role of plant hormones in plant defence responses. Plant Mol. Biol. 69, 473-488.

Barlier, I., Kowalczyk, M., Marchant, A., Ljung, K., Bhalerao, R., Bennett, M., etal. (2000). The SUR2 gene of Arabidopsis thaliana encodes the cytochrome P450 CYP83B1, a modulator of auxin homeostasis. Proc. Natl. Acad. Sci. U.S.A. 97, 1481914824.

Bekal, S., Niblack, T. L., and Lambert, K. N. (2003). A chorismate mutase from the soybean cyst nematode Heterodera glycines shows polymorphisms that correlate with virulence. Mol. Plant Microbe Interact. 16, 439446.

Belkhadir, Y., Jaillais, Y., Epple, P., Balsemão-Pires, E., Dangl, J. L., and Chory, J. (2012). Brassinosteroids modulate the efficiency of plant immune responses to microbeassociated molecular patterns. Proc Natl. Acad. Sci. U.S.A. 109, 297-302.

Berrocal-Lobo, M., Molina, A., and Solano, R. (2002). Constitutive expression of ETHYLENE-RESPONSE-FACTOR1 in Arabidopsis confers resistance to several necrotrophic fungi. Plant $J$. 29, 23-32.

Bhattacharjee, S., Halane, M. K., Kim, S. H., and Gassmann, W. (2011). Pathogen effectors target Arabidopsis EDS1 and alter its interactions with immune regulators. Science 334, 1405-1408.

Birkenbihl, R. P., Diezel, C., and Somssich, I. E. (2012). Arabidopsis WRKY33 is a key transcriptional regulator of hormonal and metabolic responses toward Botrytis cinerea infection. Plant Physiol. 159, 266-285.

Boch, J., Scholze, H., Schornack, S., Landgraf, A., Hahn, S., Kay, S., et al. (2009). Breaking the code of DNA binding specificity of TALtype III effectors. Science 326, 1509 1512.

Bogdanove, A. J., Schornack, S., and Lahaye, T. (2011). TAL effectors: finding plant genes for disease and defense. Curr. Opin. Plant Biol. 13 , 394-401.

Boller, T., and Felix, G. (2009). A renaissance of elicitors: perception of microbe-associated molecular patterns and danger signals by patternrecognition receptors. Annu. Rev. Plant Biol. 60, 379-406.

Boller, T., and He, S. Y. (2009). Innate immunity in plants: an arms race between pattern recognition receptors in plants and effectors in microbial pathogens. Science 324, 742-744.

Brandl, M. T., and Lindow, S. E. (1998). Contribution of indole-3-acetic acid production to the epiphytic fitness of Erwinia herbicola. Appl. Environ. Microbiol. 64, 3256-3263.

Brefort, T., Doehlemann, G., MendozaMendoza, A., Reissmann, S., Djamei,

\section{ACKNOWLEDGMENTS}

This work was funded by the French National Agency for Research (ANRGénoplante WALLTALK ANR-07-GPLA-014 to Deborah Goffner) and by the Ministerio de Ciencia e Innovación from Spain (grant BIO2009-07167 to Antonio Molina). Work from Deborah Goffner's group was done in the Laboratoire de Recherche en Sciences Végétales, part of the Laboratoire d'Excellence (LABEX) entitled TULIP (ANR-10-LABX-41). Andrea Sánchez-Vallet is the recipient of a Marie-Curie Cofound Postdoctoral Fellow from the Universidad Politécnica de Madrid (Spain).

A., and Kahmann, R. (2009). Ustilago maydis as a pathogen. Annu. Rev. Phytopathol. 47, 423-445.

Brooks, D. M., Bender, C. L., and Kunkel, B. N. (2005). The Pseudomonas syringae phytotoxin coronatine promotes virulence by overcoming salicylic acid-dependent defences in Arabidopsis thaliana. Mol. Plant Pathol. 6, 629-639.

Büttner, D., and He, S. Y. (2009). Type III protein secretion in plant pathogenic bacteria. Plant Physiol. 150, 1656-1664.

Cao, H., Glazebrook, J., Clarke, J. D., Volko, S., and Dong, X. (1997). The Arabidopsis NPR1 gene that controls systemic acquired resistance encodes a novel protein containing ankyrin repeats. Cell 88, 57-63.

Chen, Z., Agnew, J. L., Cohen, J. D. He, P., Shan, L., Sheen, J., et al. (2007). Pseudomonas syringae type III effector AvrRpt2 alters Arabidopsis thaliana auxin physiology. Proc. Natl. Acad. Sci. U.S.A. 104, 20131-20136.

Chen, Z., Kloek, A. P., Cuzick, A. Moeder, W., Tang, D., Innes, R. W., et al. (2004). The Pseudomonas syringae type III effector AvrRpt2 functions downstream or independently of SA to promote virulence on Arabidopsis thaliana. Plant J. 37, 494-504.

Chisholm, S. T., Coaker, G., Day, B., and Staskawicz, B. J. (2006). Host-microbe interactions: shaping the evolution of the plant immune response. Cell 124, 803-814.

Choi, S.-M., Song, H.-R., Han, S.-K., Han, M., Kim, C.-Y., Park, J., et al. (2012). HDA19 is required for the repression of salicylic acid biosynthesis and salicylic acid-mediated defense responses in Arabidopsis. Plant J. 71, 135-146.

Chung, K. R., Shilts, T., Erturk, U., Timmer, L. W., and Ueng, P. P. (2003). Indole derivatives produced by the fungus Colletotrichum acutatum causing lime anthracnose and postbloom fruit drop of citrus. FEMS Microbiol. Lett. 226, 23-30.

Chung, K. R., and Tzeng, D. D. (2004). Biosynthesis of indole-3-acetic acid by the gall-inducing fungus Ustilago esculenta. J. Biol. Sci. 4, 744-750.

Chung, Y. S., Lee, N. R., Cheon, C. L., Song, E. S., Lee, M. S., Kim, Y., et al. (2001). Molecular cloning of the nahG gene encoding salicylate hydroxylase from Pseudomonas fluorescens. Mol. Cells 11, 105-109.

Clément, M., Leonhardt, N., Droillard, M.-J., Reiter, I., Montillet, J.L., Genty, B., et al. (2011). The cytosolic/nuclear HSC70 and HSP90 molecular chaperones are important for stomatal closure and modulate abscisic acid-dependent physiological responses in Arabidopsis. Plant Physiol. 156, 1481-1492.

Conrath, U. (2011). Molecular aspects of defence priming. Trends Plant Sci. 16, 524-531.

Cui, H., Xiang, T., and Zhou, J. M. (2009). Plant immunity: a lesson from pathogenic bacterial effector proteins. Cell. Microbiol. 11, 14531461.

DebRoy, S., Thilmony, R., Kwack, Y. B., Nomura, K., and He, S. Y. (2004). A family of conserved bacterial effectors inhibits salicylic acid-mediated basal immunity and promotes disease necrosis in plants. Proc. Natl. Acad. Sci. U.S.A. 101, 9927-9932.

de Jonge, R., Bolton, M. D., and Thomma, B. P. (2011). How filamentous pathogens co-opt plants: the ins and outs of fungal effectors. Curr. Opin. Plant Biol. 14, 400-406.

Denancé, N., Ranocha, P., Oria, N., Barlet, X., Rivière, M.-P., Yadeta, K., et al. (2013). Arabidopsis watl (walls are thin1)-mediated resistance to vascular pathogens is accompanied by cross-regulation of salicylic acid and tryptophan metabolism. Plant J. 73, 225-239.

Deslandes, L., and Rivas, S. (2012). Catch me if you can: bacterial effectors and plant targets. Trends Plant Sci. 17, 644-655.

de Torres, M., Mansfield, J. W., Grabov, N., Brown, I. R., Ammouneh, H., Tsiamis, G., et al. (2006). Pseudomonas syringae effector AvrPtoB suppresses basal defence in Arabidopsis. Plant J. 47, 368-382. 
de Torres Zabala, M., Bennett, M. H., Truman, W. H., and Grant, M. R. (2009). Antagonism between salicylic and abscisic acid reflects early host-pathogen conflict and moulds plant defence responses. Plant J. 59, 375-386.

de Torres-Zabala, M., Truman, W., Bennett, M. H., Lafforgue, G., Mansfield, J. W., Rodriguez Egea, P., et al. (2007). Pseudomonas syringae pv. tomato hijacks the Arabidopsis abscisic acid signalling pathway to cause disease. EMBO J. 26, 1434-1443.

Ding, X., Cao, Y., Huang, L., Zhao, J., Xu, C., Li, X., et al. (2008). Activation of the indole-3acetic acid amido synthetase GH3-8 suppresses expansin expression and promotes salicylate- and jasmonateindependent basal immunity in rice. Plant Cell 20, 228-240.

Djamei, A., and Kahmann, R. (2012). Ustilago maydis: dissecting the molecular interface between pathogen and plant. PLoS Pathog. 8:e1002955. doi: 10.1371/journal.ppat.1002955

Djamei, A., Schipper, K., Rabe, F., Ghosh, A., Vincon, V., Kahnt, J., et al. (2011). Metabolic priming by a secreted fungal effector. Nature 478 , 395-398.

Dodds, P. N., and Rathjen, J. P. (2010). Plant immunity: towards an integrated view of plant-pathogen interactions. Nat. Rev. Genet. 11, 539-548.

Doehlemann, G., Wahl, R., Horst, R. J., Voll, L. M., Usadel, B., Poree, F., et al. (2008). Reprogramming a maize plant: transcriptional and metabolic changes induced by the fungal biotroph Ustilago maydis. Plant J. 56, 181-195.

Dong, X. (2004). NPR1, all things considered. Curr. Opin. Plant Biol. 7, 547-552.

Dörffling, K., Petersen, W., Sprecher, E., Urbasch, I., and Hanssen, H.P. (1984). Abscisic acid in phytopathogenic fungi of the genera Botrytis, Ceratocystis, Fusarium, and Rhizoctonia. Z. Naturforsch. 39, 683-684.

Dou, D., and Zhou, J.-M. (2012). Phytopathogen effectors subverting host immunity: different foes, similar battleground. Cell Host Microbe 12, 484-495.

Doyle, E. A., and Lambert, K. N. (2003). Meloidogyne javanica chorismate mutase 1 alters plant cell development. Mol. Plant Microbe Interact. 16, 123-131.

Falk, A., Feys, B. J., Frost, L. N., Jones, J. D. G., Daniels, M. J., and Parker, J. E. (1999). EDS1, an essential component of $\mathrm{R}$ gene-mediated disease resistance in Arabidopsis has homology to eukaryotic lipases. Proc. Natl. Acad. Sci. U.S.A. 96, 3292-3297.

Feng, D. X., Tasset, C., Hanemian, M. Barlet, X., Hu, J., Trémousaygue, D., et al. (2012). Biological control of bacterial wilt in Arabidopsis thaliana involves abscisic acid signalling. New Phytol. 194, 1035-1045.

Feys, B. J., Moisan, L. J., Newman, M. A., and Parker, J. E. (2001). Direct interaction between the Arabidopsis disease resistance signaling proteins, EDS1 and PAD4. EMBO J. 20, 54005411.

Feys, B. J., Wiermer, M., Bhat, R. A., Moisan, L. J., MedinaEscobar, N., Neu, C., et al. (2005). Arabidopsis SENESCENCEASSOCIATED GENE101 stabilizes and signals within an ENHANCED DISEASE SUSCEPTIBILITY1 complex in plant innate immunity. Plant Cell 17, 2601-2613.

Flors, V., Ton, J., van Doorn, R., Jakab, G., Garcia-Agustin, P., and MauchMani, B. (2008). Interplay between JA, SA and ABA signalling during basal and induced resistance against Pseudomonas syringae and Alternaria brassicicola. Plant J. 54, 81-92.

Fu, J., and Wang, S. (2011). Insights into auxin signaling in plant-pathogen interactions. Front. Plant Sci. 2:74. doi: 10.3389/fpls.2011.00074

Fu, Z. Q., Yan, S., Saleh, A., Wang, W., Ruble, J., Oka, N., et al. (2012). NPR3 and NPR4 are receptors for the immune signal salicylic acid in plants. Nature 486, 228-232.

Garcia, A. V., Blanvillain-Baufumé, S., Huibers, R. P., Wiermer, M., Li, G., Gobbato, E., et al. (2010). Balanced nuclear and cytoplasmic activities of EDS1 are required for a complete plant innate immune response. PLoS Pathog. 6:e1000970. doi: 10.1371/journal.ppat.1000970

Garcia-Andrade, J., Ramirez, V., Flors, V., and Vera, P. (2011). Arabidopsis ocp3 mutant reveals a mechanism linking $\mathrm{ABA}$ and JA to pathogeninduced callose deposition. Plant J. 67, 783-794.

Gaudin, V., and Jouanin, L. (1995). Expression of Agrobacterium rhizogenes auxin biosynthesis genes in transgenic tobacco plants. Plant $\mathrm{Mol}$ Biol. 28, 123-136.

Gimenez-Ibanez, S., and Solano, R. (2013). Nuclear jasmonate and salicylate signaling and crosstalk in defense against pathogens. Front. Plant Sci. 4:72. doi: 10.3389/fpls.2013.00072

Glazebrook, J. (2005). Contrasting mechanisms of defense against biotrophic and necrotrophic pathogens. Annu. Rev. Phytopathol 43, 205-227.

Glickmann, E., Gardan, L., Jacquet, S., Hussain, S., Elasri, M., Petit, A., et al. (1998). Auxin production is a common feature of most pathovars of Pseudomonas syringae. Mol. Plant Microbe Interact. 11 156-162.

Goel, A. K., Lundberg, D., Torres, M. A., Matthews, R., AkimotoTomiyama, C., Farmer, L., et al. (2008). The Pseudomonas syringae type III effector HopAM1 enhances virulence on water-stressed plants. Mol. Plant Microbe Interact. 21, 361-370.

Gonzalez-Lamothe, R., El Oirdi, M. Brisson, N., and Bouarab, K. (2012). The conjugated auxin indole-3-acetic acid-aspartic acid promotes plant disease development. Plant Cell 24, 762-777.

Grubb, C. D., and Abel, S. (2006). Glucosinolate metabolism and its control. Trends Plant Sci. 11, 89-100.

Guttman, D. S., Vinatzer, B. A., Sarkar, S. F., Ranall, M. V., Kettler, G., and Greenberg, J. T. (2002). A functional screen for the type III (Hrp) secretome of the plant pathogen Pseudomonas syringae. Science 295, 1722-1726.

Heidrich, K., Wirthmueller, L., Tasset, C., Pouzet, C., Deslandes, L., and Parker, J. E. (2011). Arabidopsis EDS1 connects pathogen effector recognition to cell compartmentspecific immune responses. Science 334, 1401-1404.

Hernandez-Blanco, C., Feng, D. X., Hu, J., Sanchez-Vallet, A., Deslandes, L., Llorente, F., et al. (2007). Impairment of cellulose synthases required for Arabidopsis secondary cell wall formation enhances disease resistance. Plant Cell 19, 890-903.

Hirai, N., Yoshida, R., Todoroki, Y., and Ohigashi, H. (2000). Biosynthesis of abscisic acid by the nonmevalonate pathway in plants, and by the mevalonate pathway in fungi. Biosci. Biotechnol. Biochem. 64, 14481458.

Holeski, L. M., Jander, G., and Agrawal, A. A. (2012). Transgenerational defense induction and epigenetic inheritance in plants. Trends Ecol. Evol. 27, 618-626.

Hoshi, A., Oshima, K., Kakizawa, S., Ishii, Y., Ozeki, J., Hashimoto, M., etal. (2009). A unique virulence factor for proliferation and dwarfism in plants identified from a phytopathogenic bacterium. Proc. Natl. Acad. Sci. U.S.A. 106, 6416-6421.
Howden, A. J. M., and Huitema, E. (2012). Effector-triggered posttranslational modifications and their role in suppression of plant immunity. Front. Plant Sci. 3:160. doi: 10.3389/fpls.2012.00160

Hu, J., Barlet, X., Deslandes, L., Hirsch, J., Feng, D. X., Somssich, I., et al. (2008). Transcriptional responses of Arabidopsis thaliana during wilt disease caused by the soil-borne phytopathogenic bacterium, Ralstonia solanacearum. PLoS ONE 3:e2589. doi: 10.1371/journal.pone.0002589

Hubert, D. A., Tornero, P., Belkhadir, Y., Krishna, P., Takahashi, A., Shirasu, K., etal. (2003). Cytosolic HSP90 associates with and modulates the Arabidopsis RPM1 disease resistance protein. EMBO J. 22, 5679-5689.

Inomata, M., Hirai, N., Yoshida, R., and Ohigashi, H. (2004a). Biosynthesis of abscisic acid by the direct pathway via ionylideneethane in a fungus, Cercospora cruenta. Biosci. Biotechnol. Biochem. 68, 2571-2580.

Inomata, M., Hirai, N., Yoshida, R., and Ohigashi, H. (2004b). The biosynthetic pathway to abscisic acid via ionylideneethane in the fungus Botrytis cinerea. Phytochemistry 65, 26672678.

Jaillais, Y., and Chory, J. (2010). Unraveling the paradoxes of plant hormone signaling integration. Nat. Struct. Mol. Biol. 17, 642-645.

Jelenska, J., Yao, N., Vinatzer, B. A., Wright, C. M., Brodsky, J. L., and Greenberg, J. T. (2007). A J domain virulence effector of Pseudomonas syringae remodels host chloroplasts and suppresses defenses. Curr. Biol. 17, 499-508.

Jirage, D., Tootle, T. L., Reuber, T. L., Frost, L. N., Feys, B. J., Parker, J. E., et al. (1999). Arabidopsis thaliana PAD4 encodes a lipase-like gene that is important for salicylic acid signaling. Proc. Natl. Acad. Sci. U.S.A. 96, 13583-13588.

Jones, J. D., and Dangl, J. L. (2006). The plant immune system. Nature 444, 323-329.

Kay, S., Hahn, S., Marois, E., Hause, G., and Bonas, U. (2007). A bacterial effector acts as a plant transcription factor and induces a cell size regulator. Science 318, 648-651.

Kazan, K., and Manners, J. M. (2009). Linking development to defense: auxin in plant-pathogen interactions. Trends Plant Sci. 14, 373-382.

Kempel, A., Schädler, M., Chrobock, T., Fischer, M., and van Kleunen, M. (2011). Tradeoffs associated with constitutive and induced plant resistance against herbivory. Proc. 
Natl. Acad. Sci. U.S.A. 108, 56855689.

Kettner, J., and Därffling, K. (1995). Biosynthesis and metabolism of abscisic acid in tomato leaves infected with Botrytis cinerea. Planta 196, 627-634.

Kidd, B. N., Kadoo, N. Y., Dombrecht, B., Tekeoglu, M., Gardiner, D. M., Thatcher, L. F., et al. (2011). Auxin signaling and transport promote susceptibility to the root-infecting fungal pathogen Fusarium oxysporum in Arabidopsis. Mol. Plant Microbe Interact. 24, 733-748.

Kieffer, M., Neve, J., and Kepinski, S. (2010). Defining auxin response contexts in plant development. Curr. Opin. Plant Biol. 13, 12-20.

Latzel, V., Zhang, Y., Karlsson Moritz, K., Fischer, M., and Bossdorf, O. (2012). Epigenetic variation in plant responses to defence hormones. Ann. Bot. 110, 1423-1428.

Lee, C.-W., Efetova, M., Engelmann, J. C., Kramell, R., Wasternack, C., Ludwig-Müller, J., et al. (2009). Agrobacterium tumefaciens promotes tumor induction by modulating pathogen defense in Arabidopsis thaliana. Plant Cell 21, 2948-2962.

Lee, M. W., Jelenska, J., and Greenberg, J. T. (2008). Arabidopsis proteins important for modulating defense responses to Pseudomonas syringae that secrete HopW1-1. Plant J. 54, 452-465.

Leveau, J. H., and Lindow, S. E. (2005). Utilization of the plant hormone indole-3-acetic acid for growth by Pseudomonas putida strain 1290 . Appl. Environ. Microbiol. 71, 23652371.

Liu, P., and Nester, E. W. (2006). Indoleacetic acid, a product of transferred DNA, inhibits vir gene expression and growth of Agrobacterium tumefaciens C58. Proc. Natl. Acad. Sci. U.S.A. 103, 4658-4662.

Llorente, F., Muskett, P., Sanchez-Vallet, A., Lopez, G., Ramos, B., SanchezRodriguez, C., et al. (2008). Repression of the auxin response pathway increases Arabidopsis susceptibility to necrotrophic fungi. Mol. Plant 1, 496-509.

Luna, E., Bruce, T. J., Roberts, M. R., Flors, V., and Ton, J. (2012). Nextgeneration systemic acquired resistance. Plant Physiol. 158, 844-853.

Macho, A. P., Guevara, C. M., Tornero, P., Ruiz-Albert, J., and Beuzón, C. R. (2010). The Pseudomonas syringae effector protein HopZ1a suppresses effector-triggered immunity. New Phytol. 187, 1018-1033.

Mang, H. G., Qian, W., Zhu, Y., Qian, J., Kang, H. G., Klessig, D. F. et al. (2012). Abscisic acid deficiency antagonizes high-temperature inhibition of disease resistance through enhancing nuclear accumulation of resistance proteins SNC1 and RPS4 in Arabidopsis. Plant Cell 24, 1271-1284.

Manzaneda, A. J., Kasavajhala, V. S. K., and Mitchell-Olds, T. (2010). Variation and fitness costs for tolerance to different types of herbivore damage in Boechera stricta genotypes with contrasting glucosinolate structures. New Phytol. 188, 464-477.

Maor, R., Haskin, S., Levi-Kedmi, H., and Sharon, A. (2004). In planta production of indole-3-acetic acid by Colletotrichum gloeosporioides f. sp. aeschynomene. Appl. Environ. Microbiol. 70, 1852-1854.

Marois, E., Van den Ackerveken, G., and Bonas, U. (2002). The Xanthomonas type III effector protein AvrBs3 modulates plant gene expression and induces cell hypertrophy in the susceptible host. Mol. Plant Microbe Interact. 15 637-646.

Mauch-Mani, B., and Mauch, F. (2005). The role of abscisic acid in plantpathogen interactions. Curr. Opin. Plant Biol. 8, 409-414.

Melotto, M., Underwood, W., Koczan, J., Nomura, K., and He, S. Y. (2006). Plant stomata function in innate immunity against bacterial invasion. Cell 126, 969-980.

Mohr, P. G., and Cahill, D. (2003). Abscisic acid influences the susceptibility of Arabidopsis thaliana to Pseudomonas syringae pv. tomato and Peronospora parasitica. Funct. Plant Biol. 30, 461-469.

Morgan, W., and Kamoun, S. (2007). RXLR effectors of plant pathogenic oomycetes. Curr. Opin. Microbiol. 10, 332-338.

Moscou, M. J., and Bogdanove, A. J. (2009). A simple cipher governs DNA recognition by TAL effectors. Science 326, 1501.

Navarro, L., Dunoyer, P., Jay, F., Arnold, B., Dharmasiri, N., Estelle, M., et al. (2006). A plant miRNA contributes to antibacterial resistance by repressing auxin signaling. Science 312, 436-439.

Nawrath, C., and Métraux, J. P. (1999). Salicylic acid inductiondeficient mutants of Arabidopsis express $P R-2$ and $P R-5$ and accumulate high levels of camalexin after pathogen inoculation. Plant Cell 11, 1393-1404.

Noël, L. D., Cagna, G., Stuttmann, J., Wirthmüller, L., Betsuyaku, S., Witte, C.-P., et al. (2007). Interaction between SGT1 and cytosolic/nuclear HSC70 chaperones regulates Arabidopsis immune responses. Plant Cell 19, 4061-4076.

Panstruga, R., Parker, J. E., and SchulzeLefert, P. (2009). SnapShot: plant immune response pathways. Cell 136, 978.e1-978.e3.

Park, J. E., Park, J. Y., Kim, Y. S. Staswick, P. E., Jeon, J., Yun, J., et al. (2007). GH3-mediated auxin homeostasis links growth regulation with stress adaptation response in Arabidopsis. J. Biol. Chem. 282, 1003610046.

Parker, J. E., Holub, E. B., Frost, L. N., Falk, A., Gunn, N. D., and Daniels, M. J. (1996). Characterization of eds1, a mutation in Arabidopsis suppressing resistance to Peronospora parasitica specified by several different $R P P$ genes. Plant Cell 8, 2033-2046.

Pel, M. J. C., and Pieterse, C. M. J. (2012). Microbial recognition and evasion of host immunity. J. Exp. Bot. 64, 1237-1248.

Peng, Z. Y., Zhou, X., Li, L., Yu, X., Li, H., Jiang, Z., et al. (2009). Arabidopsis hormone database: a comprehensive genetic and phenotypic information database for plant hormone research in Arabidopsis. Nucleic Acids Res. 37, D975-D982.

Petti, C., Reiber, K., Ali, S. S., Berney, M., and Doohan, F. M. (2012). Auxin as a player in the biocontrol of Fusarium head blight disease of barley and its potential as a disease control agent. BMC Plant Biol. 12:224. doi: 10.1186/1471-2229-12-224

Pieterse, C. M. J., Leon-Reyes, A., Van der Ent, S., and Van Wees, S. C. M. (2009). Networking by smallmolecule hormones in plant immunity. Nat. Chem. Biol. 5, 308-316.

Pieterse, C. M. J., van der Does, D. Zamioudis, C., Leon-Reyes, A., and van Wees, S. C. M. (2012). Hormonal modulation of plant immunity. Annu. Rev. Cell Dev. Biol. 28 489-521.

Rehmany, A. P., Gordon, A., Rose, L. E., Allen, R. L., Armstrong, M. R., Whisson, S. C., et al. (2005). Differential recognition of highly divergent downy mildew avirulence gene alleles by RPP1 resistance genes from two Arabidopsis lines. Plant Cell 17, 1839-1850.

Reineke, G., Heinze, B., Schirawski, J., Buettner, H., Kahmann, R. and Basse, C. W. (2008). Indole3 -acetic acid (IAA) biosynthesis in the smut fungus Ustilago maydis and its relevance for increased IAA levels in infected tissue and host tumour formation. Mol. Plant Pathol. 9, 339-355.
Rietz, S., Stamm, A., Malonek, S., Wagner, S., Becker, D., MedinaEscobar, N., et al. (2011). Different roles of enhanced disease susceptibilityl (EDS1) bound to and dissociated from phytoalexin deficient4 (PAD4) in Arabidopsis immunity. New Phytol. 191, 107-119.

Rivas, S., and Genin, S. (2011). A plethora of virulence strategies hidden behind nuclear targeting of microbial effectors. Front. Plant Sci. 2:104. doi: 10.3389/fpls.2011.00104

Robert-Seilaniantz, A., Grant, M., and Jones, J. D. (2011a). Hormone crosstalk in plant disease and defense: more than just jasmonate-salicylate antagonism. Annu. Rev. Phytopathol. 49, 317-343.

Robert-Seilaniantz, A., MacLean, D., Jikumaru, Y., Hill, L., Yamaguchi, S., Kamiya, Y., et al. (2011b). The microRNA miR393 re-directs secondary metabolite biosynthesis away from camalexin and towards glucosinolates. Plant J. 67, 218-231.

Robert-Seilaniantz, A., Navarro, L., Bari, R., and Jones, J. D. (2007). Pathological hormone imbalances. Curr. Opin. Plant Biol. 10, 372-379.

Robinson, M., Riov, J., and Sharon, A. (1998). Indole-3-acetic acid biosynthesis in Colletotrichum gloeosporioides f. sp. aeschynomene. Appl. Environ. Microbiol. 64, 5030-5032.

Sánchez-Vallet, A., Lopez, G., Ramos, B., Delgado-Cerezo, M., Riviere, M. P., Llorente, F., et al. (2012). Disruption of abscisic acid signalling constitutively activates Arabidopsis resistance to the necrotrophic fungus Plectosphaerella cucumerina. Plant Physiol. 160, 2109-2124.

Santner, A., Calderon-Villalobos, L. I. A., and Estelle, M. (2009). Plant hormones are versatile chemical regulators of plant growth. Nat. Chem. Biol. 5, 301-307.

Schulze-Lefert, P., and Panstruga, R. (2011). A molecular evolutionary concept connecting nonhost resistance, pathogen host range, and pathogen speciation. Trends Plant Sci. 16, 117-125.

Sequeira, L., and Williams, P. H. (1964). Synthesis of indoleacetic acid by Pseudomonas solanacearum. Phytopathology 54, 1240-1246.

Shabab, M., Shindo, T., Gu, C., Kaschani, F., Pansuriya, T., Chintha, R., etal. (2008). Fungal effector protein AVR2 targets diversifying defense-related cys proteases of tomato. Plant Cell 20, 1169-1183.

Shaul, O., Elad, Y., and Zieslin, N. (1996). Suppression of Botrytis blight in cut rose flowers with gibberellic 
acid. Effects of exogenous application of abscisic acid and paclobutrazol. Postharvest Biol. Technol. 7, 145-150.

Shi, Z., Maximova, S., Liu, Y., Verica, J., and Guiltinan, M. J. (2012). The salicylic acid receptor NPR3 is a negative regulator of the transcriptional defense response during early flower development in Arabidopsis. Mol. Plant. doi: 10.1093/mp/sss091 [Epub ahead of print].

Shinozaki, K., and YamaguchiShinozaki, K. (2007). Gene networks involved in drought stress response and tolerance. J. Exp. Bot. 58, 221-227.

Siewers, V., Kokkelink, L., Smedsgaard, J., and Tudzynski, P. (2006). Identification of an abscisic acid gene cluster in the grey mold Botrytis cinerea. App. Environ. Microbiol. 72, 4619-4626.

Siewers, V., Smedsgaard, J., and Tudzynski, P. (2004). The P450 monooxygenase $\mathrm{BCABA1}$ is essential for abscisic acid biosynthesis in Botrytis cinerea. Appl. Environ. Microbiol. 70, 38683876.

Skibbe, D. S., Doehlemann, G., Fernandes, J., and Walbot, V. (2010). Maize tumors caused by Ustilago maydis require organ-specific genes in host and pathogen. Science 328, 89-92.

Slaughter, A., Daniel, X., Flors, V., Luna, E., Hohn, B., and Mauch-Mani, B. (2012). Descendants of primed Arabidopsis plants exhibit resistance to biotic stress. Plant Physiol. 158, 835-843.

Spaepen, S., Vanderleyden, J., and Remans, R. (2007). Indole-3acetic acid in microbial and microorganism-plant signaling. FEMS Microbiol. Rev. 31, 425-448.

Spoel, S. H., Johnson, J. S., and Dong, X. (2007). Regulation of tradeoffs between plant defenses against pathogens with different life styles. Proc. Natl. Acad. Sci. U.S.A. 104, 18842-18847.

Spoel, S. H., Koornneef, A., Claessens, S. M., Korzelius, J. P., Van Pelt, J. A., Mueller, M. J., et al. (2003). NPR1 modulates cross-talk between salicylate- and jasmonate-dependent defense pathways through a novel function in the cytosol. Plant Cell 15, 760-770.
Stergiopoulos, I., and de Wit, P. J. (2009). Fungal effector proteins. Annu. Rev. Phytopathol. 47, 233-263.

Sugio, A., MacLean, A. M., Kingdom,

H. N., Grieve, V. M., Manimekalai,

R., and Hogenhout, S. A. (2011). Diverse targets of phytoplasma effectors: from plant development to defense against insects. Annu. Rev. Phytopathol. 49, 175-195.

Suzuki, S., He, Y., and Oyaizu, H. (2003). Indole-3-Acetic acid production in Pseudomonas fluorescens HP72 and its association with suppression of creeping bentgrass brown patch. Curr. Microbiol. 47, 138-143.

Swarup, R., and Péret, B. (2012). AUX/LAX family of auxin influx carriers - an overview. Front. Plant Sci. 3:225. doi: 10.3389/fpls.2012.00225

Tada, Y., Spoel, S. H., PajerowskaMukhtar, K., Mou, Z., Song, J. Wang, C., etal. (2008). Plant immunity requires conformational changes [corrected] of NPR1 via $S$ nitrosylation and thioredoxins. Science 321, 952-956.

Takahashi, A., Casais, C., Ichimura, K. and Shirasu, K. (2003). HSP90 interacts with RAR1 and SGT1 and is essential for RPS2-mediated disease resistance in Arabidopsis. Proc. Natl. Acad. Sci. U.S.A. 100, 11777-11782.

Thaler, J. S., Humphrey, P. T., and Whiteman, N. K. (2012). Evolution of jasmonate and salicylate signal crosstalk. Trends Plant Sci. 17, 260-270.

Ton, J., Flors, V., and Mauch-Mani, B. (2009). The multifaceted role of ABA in disease resistance. Trends Plant Sci. 14, 310-317.

Tsavkelova, E., Oeser, B., Oren-Young, L., Israeli, M., Sasson, Y., Tudzynski, B., et al. (2012). Identification and functional characterization of indole3-acetamide-mediated IAA biosynthesis in plant-associated Fusarium species. Fungal Genet. Biol. 49, 48-57.

Tsuda, K., Sato, M., Glazebrook, J., Cohen, J. D., and Katagiri, F. (2008). Interplay between MAMP-triggered and SA-mediated defense responses. Plant J. 53, 763-775.

Uppalapati, S. R., Ayoubi, P., Weng, H., Palmer, D. A., Mitchell, R. E., Jones, W., etal. (2005). The phytotoxin coronatine and methyl jasmonate impact multiple phytohormone pathways in tomato. Plant J. 42, 201-217.

Valls, M., Genin, S., and Boucher, C. (2006). Integrated regulation of the type III secretion system and other virulence determinants in Ralstonia solanacearum. PLoS Pathog. 2:e82. doi: 10.1371/journal.ppat.0020082

Vandeputte, O., Oden, S., Mol, A. Vereecke, D., Goethals, K., El Jaziri, M., etal. (2005). Biosynthesis of auxin by the gram-positive phytopathogen Rhodococcus fascians is controlled by compounds specific to infected plant tissues. Appl. Environ. Microbiol. 71, 1169-1177.

Vlot, A. C., Dempsey, D. M. A., and Klessig, D. F. (2009). Salicylic acid, a multifaceted hormone to combat disease. Annu. Rev. Phytopathol. 47, 177-206.

Walters, D., and Heil, M. (2007). Costs and trade-off associated with induced resistance. Physiol. Mol. Plant Pathol. 71, 3-17.

Wang, D., Pajerowska-Mukhtar, K. Culler, A. H., and Dong, X. (2007). Salicylic acid inhibits pathogen growth in plants through repression of the auxin signaling pathway. Curr. Biol. 17, 1784-1790.

Wasilewska, A., Vlad, F., Sirichandra, C., Redko, Y., Jammes, F., Valon, C., et al. (2008). An update on abscisic acid signaling in plants and more. Mol. Plant 1, 198-217.

Wu, Y., Zhang, D., Chu, J. Y., Boyle, P., Wang, Y., Brindle, I. D., et al. (2012). The Arabidopsis NPR1 protein is a receptor for the plant defense hormone salicylic acid. Cell Rep. 1, 639-647.

Yang, S., Zhang, Q., Guo, J., Charkowski, A. O., Glick, B. R., Ibekwe, A. M., et al. (2007). Global effect of indole3 -acetic acid biosynthesis on multiple virulence factors of Erwinia chrysanthemi 3937. Appl. Environ. Microbiol. 73, 1079-1088.

Yasuda, M., Ishikawa, A., Jikumaru, Y., Seki, M., Umezawa, T., Asami, T. et al. (2008). Antagonistic interaction between systemic acquired resistance and the abscisic acid-mediated abiotic stress response in Arabidopsis. Plant Cell 20, 1678-1692.
You, I. S., Ghosal, D., and Gunsalus, I. C. (1991). Nucleotide sequence analysis of the Pseudomonas putida PpG7 salicylate hydroxylase gene (nahG) and its $3^{\prime}$-flanking region. Biochemistry 30, 1635-1641.

Zeng, W., Brutus, A., Kremer, J. M., Withers, J. C., Gao, X., Jones, A. D., et al. (2011). A genetic screen reveals Arabidopsis stomatal and/or apoplastic defenses against Pseudomonas syringae pv. tomato DC3000. PLoS Pathog. 7:e1002291. doi: 10.1371/journal.ppat.1002291

Zhang, X., Wang, C., Zhang, Y., Sun, Y., and Mou, Z. (2012). The Arabidopsis mediator complex subunit 16 positively regulates salicylate-mediated systemic acquired resistance and jasmonate/ethylene-induced defense pathways. Plant Cell 24, 4294-4309.

Zheng, X. Y., Spivey, N. W., Zeng, W., Liu, P. P., Fu, Z. Q., Klessig, D. F., et al. (2012). Coronatine promotes Pseudomonas syringae virulence in plants by activating a signaling cascade that inhibits salicylic acid accumulation. Cell Host Microbe 11, 587-96.

Conflict of Interest Statement: The authors declare that the research was conducted in the absence of any commercial or financial relationships that could be construed as a potential conflict of interest.

Received: 14 January 2013; accepted: 05 May 2013; published online: 24 May 2013.

Citation: Denancé N, Sánchez-Vallet A, Goffner D and Molina A (2013) Disease resistance or growth: the role of plant hormones in balancing immune responses and fitness costs. Front. Plant Sci. 4:155. doi: 10.3389/fpls.2013.00155

This article was submitted to Frontiers in Plant Cell Biology, a specialty of Frontiers in Plant Science.

Copyright (c) 2013 Denancé, SánchezVallet, Goffner and Molina. This is an open-access article distributed under the terms of the Creative Commons Attribution License, which permits use, distribution and reproduction in other forums, provided the original authors and source are credited and subject to any copyright notices concerning any thirdparty graphics etc. 